Original article

\title{
STUDIES ON THE SPECIFIC IMMUNODIAGNOSIS OF CYSTIC ECHINOCOCCOSIS IN CAMELS USING ENZYME-LINKED IMMUNOSORBENT ASSAY
}

\author{
O. M. KANDIL, N. M. F. HASSAN, D. SEDKY \& E. BESHIR ATA \\ Department of Parasitology and Animal Diseases, National Research Centre, \\ Cairo, Egypt
}

\begin{abstract}
Summary
Kandil, O. M., N. M. F. Hassan, D. Sedky \& E. Beshir Ata, 2019. Studies on the specific immunodiagnosis of cystic echinococcosis in camels using enzyme-linked immunosorbent assay. Bulg. J. Vet. Med., 22, No 3, 305-313.

Cystic echinococcosis (CE) is of increasing public health and socio-economic concern because of the large morbidity rates and produced high economic losses in the livestock industry. The objective of the current research was to study the reliability of indirect ELISA in detecting CE, based on two different types of crude antigens of camel origin; protoscolex and germinal layer antigens from hydatid cyst. Blood samples were collected from 284 (125 slaughtered and 159 live camels). Out of 125 slaughtered camels examined visually, 55 (44\%) were found to have hydatid cysts. Of them, 52/125 $(41.6 \%)$ and $3 / 125(2.4 \%)$ harboured hydatid cysts in lungs and livers respectively. Fertile lung cysts were $32.8 \% ; 26.9 \%$ were sterile, while $40.3 \%$ of lung and liver cysts were calcified. The sensitivity of ELISA was $83 \%$ and $46.5 \%$ when protoscolex and germinal layer antigens were used, respectively. The respective specificity of antigens of protoscolex and germinal layer was $70.3 \%$ and $41.7 \%$. The protoscolex antigen showed higher accuracy (73.6\%) compared to the germinal layer antigen $(52.8 \%)$. The cross reactivity of these antigens were evaluated with antigens and hyperimmune sera of $\mathrm{CE}$ and Fasciola spp. and Haemonchus contortus using ELISA. The results showed also weak immunogenic potency of each antigen with Fasciola spp. hyperimmune sera at dilution 1:50 while hyperimmune sera of Haemonchus contortus did not bind any antigen.
\end{abstract}

Key words: antigen, camel, cystic echinococcosis, ELISA, Fasciola, Haemonchus

\section{INTRODUCTION}

Cystic echinococcosis (CE; hydatidosis) is one of the widely distributed parasitic diseases with zoonotic importance. It is caused by ingestion of different Echinococcus species eggs (Samorek-Pieróg et al., 2016). The adult worm inhabits the small intestine of dogs as permanent hosts, while the larval stages or hydatid cysts occur in herbivorous intermediate hosts and sometimes in humans (Almalki et al., 2017). The disease can infect different animal species including camels with variable rates of infection (Kandil et al., 2016). Loss of body weight, decreased 
fertility rate, and reduction of milk and wool production are the major clinical signs of infection (Torgerson, 2003). Abattoir surveys are important, particularly in the surveillance of many parasitic diseases including CE (Borji et al., 2012). Definite diagnosis of Echinococcus granulosus infection in animals is the first step for epidemiological studies and surveillance either in endemic, re-emergent or emergent transmission areas (Craig et al., 2015). No direct parasitological evidence was found for the presence of cysts in organs or tissues and in most cases, the early stages of infection are asymptomatic.

Imaging techniques, for example, ultrasound (US), computed tomography (CT) and magnetic resonance imaging (MRI) are utilised as often as possible for diagnosing CE. Ultrasound has been used widely because it is simple, noninvasive, and cost-effective (Ozkol et al., 2005). However, the accuracy of US-based screening relies greatly on the skills of the ultrasonographer (Yu et al., 2008). Han et al. (2016) demonstrated that ultrasonography appears to be the detection modality of choice. Serology could be used for detection of infection in the suspected individuals, especially when it is complicated to differentiate between some cyst stages from the common non-parasitic cysts (Brunetti et al., 2011). The accessibility of suitable serodiagnostic tools including enzyme-linked immunosorbent assay (ELISA) could help in diagnosing many infectious diseases in camels (AlRuwaili et al., 2012; Mohamed et al., 2013). Indeed, there are few serological studies on camel CE. Unfortunately local commercial anti-camel immunoglobulins are not currently available that is considered a main obstacle to diagnosis of camel antibodies using ELISA. However, it has been obtainable for many various parasitic research studies (Azwai et al., 1995), so sero-diagnostic studies should be directed to this significant and functional aspect.

The present study was aimed at evaluating native crude antigens of protoscolex and germinal layer implemented in ELISA for detection of specific IgG antibodies of $\mathrm{CE}$ in camels' serum samples collected from Egyptian abattoirs and markets.

\section{MATERIALS AND METHODS}

\section{Ethical approval}

All animal experimental procedures were performed in accordance with the recommendations and guidelines stated by the ethical Committee of the National Research Centre under certificate number 17133.

\section{Samples collection}

Hydatid cysts were collected from the lung and liver of camels slaughtered at Cairo abattoir (EL-Basatin). One hundred and twenty five animals were visually examined after slaughtering. Infected camels were recorded and infected organs (52 lungs and 3 livers) were collected. Sixty seven hydatid cysts were removed carefully from their host tissue without injuring the cystic wall, washed thoroughly with tape water, rewashed in saline and kept in phosphate buffered saline (PBS) until use (Ahmed et al., 2006). The viability of protoscolex was determined by using eosin exclusion $10 \%$ solution (Macpherson et al., 1985). Adult worms of Haemonchus contortus and Fasciola gigantica were collected from slaughtered sheep at EL-Basatin abattoir in Egypt. Worm recovery was carried out according to standard procedures (MAFF, 1986). 


\section{Antigens preparation}

The adult Haemonchus contortus worms, Fasciola species, germinal layer and protoscolex of hydatid cyst were washed with PBS and subjected to grinding using a homogeniser followed by sonication and high-speed cooling centrifugation $(14,000$ rpm for $30 \mathrm{~min})$. The supernatant was obtained and the process of centrifugation was repeated twice till no sediment was thrown down (Ahmed et al., 2006). The protein content of the different prepared antigens was determined according to Lowry et al. (1951).

\section{Serum samples}

Blood samples were collected from 284 camels included 125 slaughtered camels at El-Basateen abattoir, Cairo, and 159 randomly selected live camels from the market. Serum samples were prepared and kept at $-20{ }^{\circ} \mathrm{C}$ until used.

\section{Hyperimmune sera}

Fifteen healthy White New Zealand male rabbits around $1.5-2 \mathrm{~kg}$ body weight were grouped in 5 groups $(\mathrm{n}=3)$ and immunised with the different prepared crude antigens (germinal layer, protoscolex, Fasciola species and Haemonchus contortus). One group was kept as a control. Hyperimmune sera were prepared according to Fagbemi et al. (1995).

\section{Serological analysis}

The potency of protoscolex and germinal layer antigens was evaluated by ELISA which was performed according to Sadjjadi et al. (2007). The optimal antigen, serum and conjugate concentrations were determined after preliminary checkerboard titration according to Catty \& Raykundalia (1989). The antigen concentration was $20 \mu \mathrm{g} / \mathrm{mL}$ and $40 \mu \mathrm{g} / \mathrm{mL}$ for germinal layer and protoscolex antigens respectively. After coating, blocking with $100 \mu \mathrm{L}$ per well of $0.1 \%$ bovine serum albumin in $0.01 \mathrm{M}$ PBS was done. From the natural infected sera of $\mathrm{CE}$, noninfected sera, random sera from live camels and hyperimmune sera of CE, Haemonchus contortus and Fasciola species (diluted 1:50, 1:100, 1:200 in PBS), 100 $\mu \mathrm{L}$ were added to each well. One hundred $\mu \mathrm{L}$ of 1:1000 peroxidase conjugate antibovine IgG were used. Fifty $\mu \mathrm{L}$ of orthophenylenediamine was used as a substrate. The reaction was terminated with $1 \mathrm{M}$ $\mathrm{H}_{2} \mathrm{SO}_{4}$ and the absorbance values were read spectrophotometrically at $490 \mathrm{~nm}$. Positive samples were assigned according to Rodriguez-Perez \& Hillyer (1995) as those with absorbance readings greater than the cut-off value, which was calculated as mean OD of negative sera plus three standard deviations. Sensitivity, specificity and accuracy of ELISA were calculated as described by Timmreck (1994).

\section{Statistical analysis}

OD data were expressed as arithmetic mean with standard deviation. The apparent prevalence parameter was analysed using the Chi square test by statistical computer package for social science (SPSS) version 15.

\section{RESULTS}

\section{Post mortem findings and CE infection percentage}

Out of 125 slaughtered camels examined visually, 55 (44\%) camels were infected with hydatid cyst and 70 (56\%) were naturally non-infected camels. Fifty two lungs and three livers harboured hydatid cyst with infection percentage $41.6 \%$ and $2.4 \%$ respectively. The lungs were the most 
Studies on the specific immunodiagnosis of cystic echinococcosis in camels using enzyme-linked ...

commonly affected organs with hydatid cysts. The examination of lung cysts demonstrated that 22 or $32.8 \%$ and 18 or $26.9 \%$ appeared fertile and sterile, while $40.3 \%$ of lung and liver cysts were calcified.

\section{Immunogenic reactivity of different CE antigens}

Two hundred and eighty four camel's sera were tested by ELISA using the protoscolex and germinal layer antigens to detect CE antibodies. The seropositive samples using protoscolex and germinal layer antigens were $89(31.3 \%)$ and 144 $(50.7 \%)$ respectively (Table 1$)$. Most of the naturally infected camels were true positive -28 and 27 using the protoscolex and germinal layer antigens respectively, while 27 and 28 false positive results were respectively recorded. Therefore, the results of ELISA showed that the germinal layer antigen detected the higher prevalence $(44.3 \%)$ and protoscolex antigen noticed a lower prevalence $(8.6 \%)$ of noninfected sera from slaughtered camels. Moreover, the germinal layer antigen had a higher diagnostic efficacy (54\%) than the protoscolex antigen (34.6\%) from random live camel sera. Nevertheless, sensitivity of ELISA was $83 \%$ and $46.5 \%$ when the protoscolex and germinal layer antigens were used, respectively. The specificity of antigens of protoscolex and germinal layer were $70.3 \%$ and $41.7 \%$. The protoscolex antigen showed higher accuracy value $(73.6 \%)$ compared to the germinal layer antigen $(52.8 \%)$.

The diagnostic performances of the two antigens used in the study were evalu-

Table 1. Detection of anti-CE antibodies in sera from slaughtered camels compared to live camels findings

\begin{tabular}{lccccc}
\hline Parameter & Animal & \multicolumn{5}{c}{ Types of antigens } \\
\cline { 3 - 6 } & number & & \multicolumn{2}{c}{ Protoscolex } & \multicolumn{2}{c}{ Germinal layer } \\
\cline { 3 - 6 } & & + & $\%$ & + & $\%$ \\
\hline $\begin{array}{l}\text { Naturally } \\
\text { infected sera }\end{array}$ & 55 & 28 & 50.9 & 27 & 49.0 \\
$\begin{array}{l}\text { Naturally non- } \\
\text { infected sera }\end{array}$ & 70 & 6 & 8.6 & 31 & 44.3 \\
Random sera & 159 & 55 & 34.6 & 86 & 54.0 \\
\hline Total & 284 & 89 & 31.3 & 144 & 50.7 \\
\hline
\end{tabular}

Table 2. Comparison between protoscolex and germinal layer antigens for naturally infected sera (IS), non-infected sera (NIS) and random sera from camels (Chi-square test results)

\begin{tabular}{|c|c|c|c|c|}
\hline \multirow[t]{2}{*}{ Groups } & \multicolumn{2}{|c|}{ Protoscolex antigen } & \multicolumn{2}{|c|}{ Germinal layer antigen } \\
\hline & $\chi^{2}$ & Significance & $\chi^{2}$ & Significance \\
\hline IS $v s$ NIS & 14.235 & $<0.001$ & 0.276 & 0.599 \\
\hline IS $v s$ random & 8.783 & 0.003 & 30.805 & $<0.001$ \\
\hline NIS $v s$ random & 39.361 & $<0.001$ & 25.855 & $<0.001$ \\
\hline
\end{tabular}




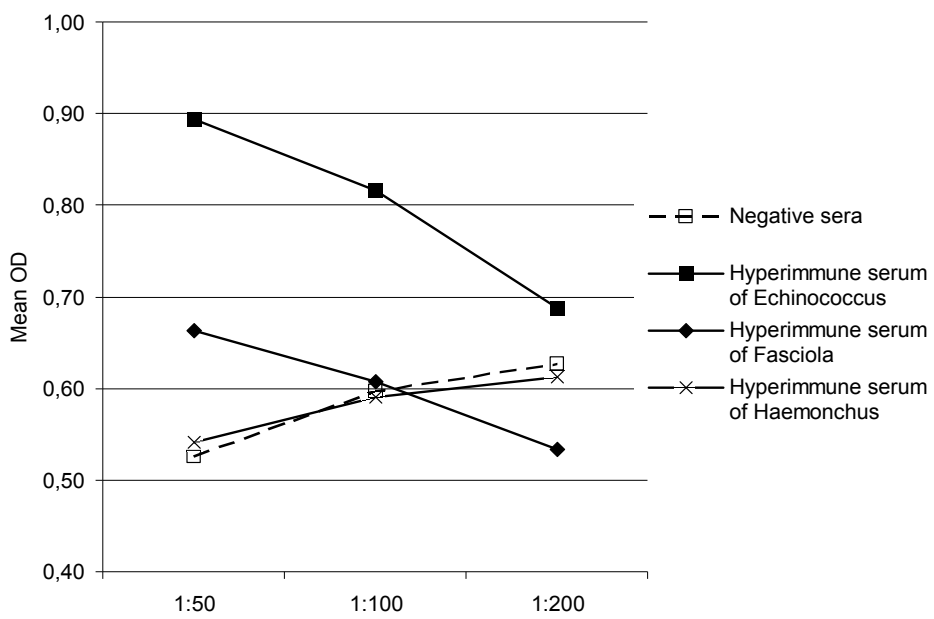

Fig. 1. Cross reactivity of the protoscolex antigen against negative rabbit serum, hyperimmune sera raised against $\mathrm{CE}$ as positive control, Fasciola species and Haemonchus contortus.

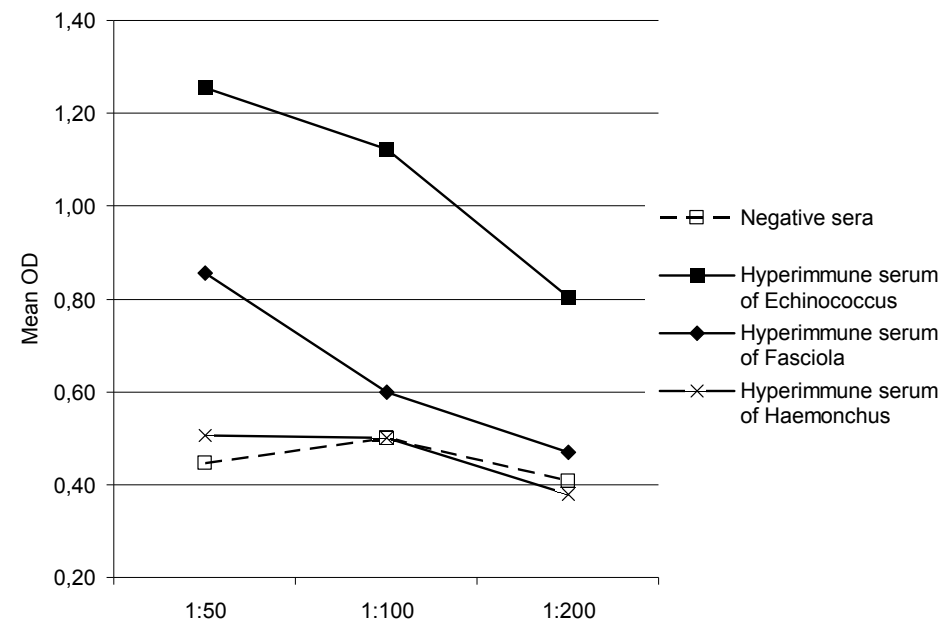

Fig. 2. Cross reactivity of the germinal layer antigen against negative rabbit serum, hyperimmune sera raised against $\mathrm{CE}$ as positive control, Fasciola species and Haemonchus contortus.

ated then statistically compared using a $\chi^{2}$ test (Table 2). It is shown that the protoscolex antigen was the best antigen used for diagnosis of $\mathrm{CE}$ as the statistical analysis using Chi square test found that IS vs NIS, IS vs Random and NIS vs random differed significantly $(\mathrm{P}<0.05)$, while the germinal layer antigen IS vs NIS showed no significant difference.

The results of cross reactivity of protoscolex and germinal layer antigens with different hyperimmune of CE, Fasciola spp and Haemonchus contortus showed that the immunogenic potency of each 
Studies on the specific immunodiagnosis of cystic echinococcosis in camels using enzyme-linked ...

antigen was weak with Fasciola spp. hyperimmune sera (1:50) while hyperimmune sera of Haemonchus contortus did not bind any antigen (Fig. 1 and 2).

\section{DISCUSSION}

Hydatidosis is considered as an important zoonotic disease, of serious livestock and human health concern in the Mediterranean region and in the world (Adel et al., 2017; Belmamoun et al., 2017). Annual losses of animal production due to the hydatid cysts, have been estimated to between 142 and 2190 million US dollars around the world (Moro et al., 2011).

The obtained results evidence that out of 125 slaughtered camels examined visually and manually by palpation and incision, 55 (44\%) were found to have hydatid cysts $(41.6 \%)$ in lungs and $(2.4 \%)$ in liver indicating that lungs are the usual and the most infected organ by hydatid cysts. These results appeared to be in line with that obtained by Rinaldi et al. (2008) in Italy and Beyhan \& Umur (2011) in Turkey, who stated that lungs were the extremely affected organ with CE in buffaloes $(80 \%$ out of the examined animals). Moreover, the results coincided with that of Debas \& Ibrahim (2013) who reported that the cyst could be developed in different parts of animal body but the most predilection sites are the lungs and the liver and at a lesser extent, the spleen and the heart.

Our results disagreed with those obtained by Ahmed et al. (2017) who revealed that liver was the most commonly affected organ which might be due to the reflection of the route of parasite entry and seems to support the hypothesis of hepatic portal distribution of oncospheres resulting in liver infection firstly. Out of the total 67 cysts collected, 22 (32.8\%),
$18(26.9 \%)$ and $27(40.3 \%)$ were fertile, sterile and calcified respectively. Haroun et al. (2008) found $6.3 \%$ fertile hydatid cyst which is a lower incidence than presented obtained results. Variation in fertility could be attributed to strain differences such as host and organ preference, development rate, infectivity, pathogenesis and antigenicity and drug resistance (Thompson \& Lymbery, 1988).

Diagnosis is a basic step in studies of echinococcosis (Barnes et al., 2006). Using specific serological techniques for diagnosis of CE in camels would be helpful for screening the hydatid infection in commercial and domesticated animals and for epidemiological investigations (Han et al., 2016). ELISA has been produced for serodiagnosis of animal CE; however, to the best of our knowledge, this is the first study that demonstrates an assay for determination of specific IgG against hydatid antigens in camel sera. Thus, in the present study, the protoscolex and germinal layer antigens of camel origin were successfully used in ELISA to detect specific IgGs in camel sera, determined post mortem to be naturally infected by $\mathrm{CE}$. Craig \& Rickard (1981) found that hydatid cyst fluid antigen is good for diagnosis of CE because the fluid from fertile cysts has been found to contain high concentrations of diagnostically relevant antigens but also components, mainly immunoglobulins and serum albumin, interfering with diagnostic tests (Sanchez \& Sanchez, 1971). The present ELISA results showed $31.3 \%$ and $50.7 \%$ seropositive samples with CE using protoscolex and germinal layer antigens respectively compared with $44 \%$ positivity from the post mortem examination. This may be attributed to absence of antibodies production as in case of small cysts, intact cysts, and or calcified cysts existence (Gavidia et al., 
2008). However, many serological methods including ELISA, were used for the diagnosis due to advantages in aspect of the collection, storage and transportation (Zhang et al., 2012).

The sensitivity for the protoscolex was $83 \%$ as compared to $46.5 \%$ for germinal layer according to the visual inspection of liver and lungs; on the other hand a negative result was obtained in slaughtered camels judged visually to be not infected with hydatidosis. The specificity of the ELISA was not as high $70.3 \%$ and $41.7 \%$ for the protoscolex and germinal layer antigens respectively. The obtained false positive results might be secondary to cross reactions with other parasitic infections. Many factors affect IgG production, like cyst number, size, location, and stage (Moro \& Schantz, 2009). Moreover, serological techniques' sensitivity is inversely related to the degree of sequestration of the echinococcal antigens inside cysts (Nunnari et al., 2012). Moreover, Ibrahem \& Criag (1998) showed that antigen B purified from hydatid cyst fluid was highly specific (99\%) and sensitive (90\%) when used in ELISA to test sera collected from sheep naturally infected with CE. Thus ELISA may be considered a highly sensitive and specific tool for CE diagnosis.

So, the present study concluded that the protoscolex antigen from camel hydatid cyst is a promising antigen for serological diagnosis and screening of $\mathrm{CE}$ in camels.

\section{ACKNOWLEDGEMENTS}

This work was financially supported by coproject between Egypt and Morocco entitled "Impact of agricultural wastewaters reuse on human and animals parasites; Diagnosis, cycle and epidemiology of hydatidosis" and funded from Ministry of Scientific Research in Egypt.

\section{REFERENCES}

Adel, F., J. M. Ramia, L. Gijón, R. de la PlazaLlamas, V. Arteaga-Peralta \& C. RamiroPerez, 2017. Extrahepatic and extrapulmonary hydatidosis. Cirugíay Cirujanos, $\mathbf{8 5}$, 121-126.

Ahmed, K. D., M. M. Ghada \& H. A. E. Osama, 2017. Seroprevalence of hydatidosis in camels of Assuit Province, Egypt. Madridge Journal of Vaccine, 1,1-4.

Ahmed, S., M. Nawaz, R. Gul, M. Zakir \& A. Razzaq, 2006. Some epidemiological aspects of hydatidosis of lungs and livers of sheep and goats in Quetta, Pakistan. Pakistan Journal of Zoology, 38, 1-6.

Almalki, E., S. Al-Quarishy \& A. S. AbdelBaki, 2017. Assessment of prevalence of hydatidosis in slaughtered Sawakny sheep in Riyadh city Saudi Arabia. Saudi Journal of Biological Science, 24, 1534-1537.

Al-Ruwaili, M. A., O. M. Khalil \& S. A. Selim, 2012. Viral and bacterial infections associated with camel (Camelus dromedarius) calf diarrhea in North Province, Saudi Journal of Biological Science, 19, 35-41.

Azwai, S., S. Carter \& Z. Woldehiwet, 1995. Monoclonal antibodies against camel $(\mathrm{Ca}$ melus dromedarius) IgG, IgM and light chains. Veterinary Immunology and Immunopathology, 45, 175-184.

Barnes T. S., P. Deplazes, B. Gottstein, D. J. Jenkins, A. Mathis, M. Siles-Lucas, P. R. Torgerson, I. Ziadinov \& D. D. Heath, 2006. Challenges for diagnosis and control of cystic hydatid disease. Acta Tropica, 123, 1-7.

Belmamoun, A. R., A. Ammam \& I. Berrabah, 2017. Prevalence of hydatidosis in liver and lungs and its economic impact in slaughtered ruminants in Sidi-Bel-Abbes, Algeria. Journal of Applied Environmental and Biological Sciences, 8, 18-23.

Beyhan, Y. E. \& S. I. Umur, 2011. Molecular characterization and prevalence of cystic echinococcosis in slaughtered water buffa- 
Studies on the specific immunodiagnosis of cystic echinococcosis in camels using enzyme-linked ...

loes in Turkey. Veterinary Parasitology, 181, 174-179.

Borji, H., M. Azizzadeh \& M. Kamelli, 2012. A retrospective study of abattoir condemnation due to parasitic infections: Economic importance in Ahwaz, Southwestern Iran. Journal of Parasitology, 98, 954957.

Brunetti, E., H. H. Garcia \& T. Junghanss, 2011. Cystic echinococcosis: chronic, complex, and still neglected. PLoS $\mathrm{Ne}$ glected Tropical Disease, 5, E1146.

Catty, D. \& C. Raykundalia, 1989. ELISA and related enzyme immunoassays. In: $A n-$ tibodies, A Practical Approach, Oxford University, London, pp. 97-152.

Craig, P. S. \& M. D. Rickard, 1981. Studies on the specific immunodiagnosis of larval cestode infections of cattle and sheep using antigens purified by affinity chromatography. International Journal for Parasitology, 11, 441-449.

Craig, P., A. Mastin, F. Van Kesteren \& B.Boufana, 2015. Echinococcus granulosus: Epidemiology and state-of-the-art of diagnostics in animals. Veterinary Parasitology, 213, 132-148.

Debas, E. \& N. Ibrahim, 2013. Prevalence and economic importance of hydatidosis in cattle slaughtered at North Gonder Elfora abattoir. European Journal of Applied Science, 55, 29-35.

Fagbemi, B. O., I. O. Obarisiagbon \& J. V. Mbuh,1995. Detection of circulating antigen in sera of $F$. gigantica infected cattle with antibodies reactive with a Fasciola specific $88 \mathrm{kDa}$ antigen. Veterinary Parasitology, 58, 235-246.

Gavidia, C. M., A. E. Gonzalez, W. Zhang, D. P. Mcmanus, L. Lopera, B. Ninaquispe, H. H. Garcia, S. Rodriguez, M. Verastegui, C. Calderon, W. K. Pan \& R. H. Gilman, 2008. Diagnosis of cystic echinococcosis, central peruvian highlands. Emerging Infectious Diseases, 14, 260-266.

Han, S., R. Chen, W. Fang, F. Fu, J. Wen, X. Zhang \& X. Ma, 2016. Investigation of the use of serology and ultrasonography to de- tect hepatic cystic echinococcosis in Heilongjiang, China, using a Bayesian frame work. Acta Tropica, 162, 212-217.

Haroun, E. M., O. H. Omer, O. M. Mahmoud \& A. Draz, 2008. Serological studies on hydatidosis in camels in Saudi Arabia. Research Journal of Veterinary Science, $\mathbf{1}$, 71-73.

Kandil, O. M., K. A. Abdelrahman, N. M. T. Abu El Ezz \& V. Antonio, 2016. Genetic Diversity of Echinococcus granlosus isolated from farm animals by using nuclear and mitochondrial genetic loci. International Journal of ChemTech Research, 9, 169-177.

Lowry, O. H., N. J. Rosebrough, A. L. Farr \& R. J. Randall, 1951. Protein measurement with the folin phenol reagent. The Journal of Biological Chemistry, 193, 265-275.

Macpherson, C. N. L., C. M. French, P. Stevenson, L. Karstad \& J. Arundel, 1985. Hydatid disease in the Turkana District of Kenya. The prevalence of Echinococcus granulosus infections in dogs and observations on the role of the dog in the life style of the Turkana. Annals of Tropical medecine and Parasitology, 79, 51-61.

MAFF (Ministry of Agriculture, Fisheries and Food), 1986. Manual of Veterinary Parasitological Laboratory Techniques, HSMO Publications, London.

Mohamed, M. A., M. T. Shigidy \& A. Y. Juboori, 2013. Sero-prevalence and epidemiology of brucellosis in camels, sheep and goats in Abu Dhabi Emirate. International Journal of Animal Veterinary Advances, 5, 82-86.

Moro, P. A. \& P. M. Schantz, 2009. Echinococcosis: A review. International Journal of Infectious Diseases, 13, 125-133.

Moro, P. L., C. M. Budke, P. M. Schantz, J. Vasquez, S. J. Santivanez \& J. Villavicencio, 2011. Economic impact of cystic echinococcosis in Peru. PLoS Neglected Tropical Diseases, 5, e1179.

Nunnari, G., M. P. Pinzone, S. Gruttadauria, B. M. Celesia, G. Madeddu, G. Malaguar- 
nera, P. Pavone, A. Cappellani \& B. Cacopardo, 2012. Hepaticechinococcosis: Clinical and therapeutic aspects. World Journal of Gastroenterology, 18, 1448-1458.

Ozkol, M., A. A. Kilimcioglu, N. Girginkardesler, I. C. Balcioglu, N. Sakru, M. Korkmaz \& U. Z. Ok, 2005. A discrepancy between cystic echinococcosis confirmed by ultrasound and seropositivity in Turkish children. Acta Tropica, 93, 213-216.

Rinaldi, L., M. P. Maurelli, F. Capuano, A. G. Perugini, V. Veneziano \& S. Cringoli, 2008. Molecular update on cystic echinococcosis in cattle and buffaloes of Southern Italy. Zoonoses and Public Health, 55, 119-123.

Rodriguez-Perez \& G. V. Hillyer, 1995. Detection of excretory-secretory circulating antigens in sheep infected with Fasciola heptica and with Schistosoma mansoi and Fasciola hepatica . Veterinary Parasitology, 56, 57-66.

Sadjjadi, S., H. Abidi, B. Sarkar, A. Izadpanah \& S. Kazemian, 2007. Evaluation of enzyme linked imunosorbant assay, utilizing native antigen $\mathrm{B}$ for serodiagnosis of human hydatidosis. Iranian Journal of Immunology, 3, 167-172.

Samorek-Pieróg, M., J. Karamon \& T. Cencek, 2016. Echinococcus granulosus - a global zoonotic problem and diagnostic possibilities in animals. Medycyna Weterynaryjna, 72, 728-734.

Sanchez, A. F. \& A. C. Sanchez, 1971. Estudio de algunas propiedades físicas y componentes quimicos del liquido y pared germinativa de quistes hidáticos de diversas especies y de diferente localización. Revista Ibérica de Parasitologia, 31, 347-366.
Thompson, R. C. \& A. J. Lymbery, 1988. The nature, extent and significance of variation with in the genus Echinococcus. Advances in Parasitology, 27, 209-225.

Timmreck, T. C., 1994. An Introduction to Epidemiology, Jones and Barlett Publ., Boston and London and Singapore.

Torgerson, P. R., 2003. Economic effect of echinococcosis. Acta Tropica, 85, 113118.

Yu, S. H., H. Wang, X. H. Wu, X. Ma, P. Y. Liu, Y. F. Liu, Y. M. Zhao, Y. Morishima \& M. Kawanaka, 2008. Cystic and alveolar echinococcosis: An epidemiological survey in a tibetan population in southeast Qinghai, China. Japanese Journal of Infectious diseases, 61, 242.

Zhang, W., H. Wen, J. Li, R. Lin \& D. P. Mcmanus, 2012. Immunology and immunodiagnosis of cystic echinococcosis: An update. Clinical and Developmental Immunology, 2012, 10101895.

Paper received 02.01.2018; accepted for publication 16.03.2018

\section{Correspondence:}

Omnia M. Kandil

Department of Parasitology and

Animal Diseases,

National Research Centre,

El-Bohouth Street, Dokki,

P.O. Box 12622,

Cairo, Egypt

tel: +01005414113 ,

e-mail:kandil_om@yahoo.com 